\title{
A Disciplina de Matemática na Escola Técnica Nacional
}

\author{
(1942-1965)
}

\section{The Subject of Mathematics at the National Technical School}

\author{
$(1942-1965)$
}

\author{
Paulo Roberto Castor Maciel ${ }^{*}$ \\ ORCID iD 0000-0001-5558-8874
}

\begin{abstract}
Resumo
O presente artigo tem como objetivo analisar a disciplina de Matemática na Escola Técnica Nacional (ETN) durante o período de 1942 a 1965. Como aporte teórico-metodológico, recorremos às ideias sobre história das disciplinas escolares de Chervel (1990), que indica a investigação de uma disciplina a partir de objetivos fixados e práticas pedagógicas realizadas e pelos itens constituintes (exposição de conteúdos, práticas de incitação e motivação, exercícios e aparelho docimológico). As fontes históricas utilizadas foram: legislação, programas, livros didáticos, apostilas e provas. A partir dos vestígios do passado, constatamos similaridades e diferenças com o Ensino Secundário. A disciplina se constituiu como uma representação de uma Matemática para a oficina, mas há muitas apropriações do Ensino Secundário.
\end{abstract}

Palavras-chave: História das Disciplinas Escolares. Matemática. Ensino Industrial. ETN.

\begin{abstract}
The present paper aims to analyze the Mathematics discipline at the National Technical School (ETN) from 1942 to 1965. As a theoretical-methodological contribution, we resort to ideas on the history of school subjects by Chervel (1990), which indicates the investigation of a discipline from setting objectives and pedagogical practices carried out and by the constituent items (exhibition of contents, practices of encouragement and motivation, exercises, and docimological apparatus). The historical sources used were: legislation, programs, textbooks, handouts, and tests. From the vestiges of the past, we see similarities and differences with secondary education. The subject was constituted as a representation of mathematics for the manufactory, but there are many appropriations of secondary education.
\end{abstract}

Keywords: History of School Subjects. Mathematics. Industrial Education. ETN.

\section{Introdução}

A disciplina de Matemática no Ensino Secundário é tema de estudo de várias pesquisas, por exemplo: Valente (2004a; 2004b; 2004c; 2007; 2011), Dassie (2001), Pires

\footnotetext{
* Doutor em Ciência, Tecnologia e Educação, Centro Federal de Educação Tecnologica Celso Suckow da Fonseça (CEFET/RJ). Professor do Departamento de Educação Matemática da Faculdade de Educação da Baixada Fluminense da Universidade do Estado do Rio de Janeiro (UERJ), Duque de Caxias, Rio de Janeiro, Brasil. Endereço para correspondência: Rua General Manoel Rabelo, s/n ${ }^{\circ}$, Vila São Luis, Duque de Caxias, Rio de Janeiro, Brasil, CEP: 25065-050. E-mail: prcastor@ hotmail.com.
} 
(2004), Marques (2005), Alvarez (2004), Ribeiro (2006; 2011), Otone (2011) e Oliveira Filho (2013). Por outro lado, verificamos que há poucas investigações ${ }^{1}$ sobre a disciplina no Ensino Industrial e, dentre elas, destacamos: Pinto (2006), Moura (2012; 2016), Silva (2015) e Novaes $(2007 ; 2012)$. Notamos que há uma potencialidade de abordar a temática dos saberes matemáticos na Escola Técnica Nacional (ETN), uma vez que há lacunas sobre o tipo de disciplina nessa modalidade de ensino.

A ETN passou por várias mudanças até se transformar no Centro Federal de Educação Tecnológica Celso Suckow da Fonseca (CEFET/RJ), que atualmente oferece cursos de Ensino Médio, Ensino Técnico, Ensino Superior, Pós-Graduação lato-sensu e stricto sensu.

Destarte, a referida instituição foi produto de disputas e avanços para a consolidação de educação de qualidade e de oferta de mão de obra qualificada à demanda social, então, para compreender esse atual status, é necessário conhecer a história dessa instituição.

Em 1917 foi criada a Escola Normal de Artes e Ofícios Venceslau Brás por meio do Decreto Municipal $\mathrm{n}^{\mathrm{o}} 1.880$, de 11 de agosto de 1917, na cidade do Rio de Janeiro, então Distrito Federal. O objetivo com a criação dessa escola era a formação de mestres e contramestres para ensinarem na Educação Profissional e a capacitação docente para aqueles que ensinassem trabalhos manuais nas Escolas Primárias (SILVEIRA, 2006).

De acordo com Cardoso (2013), desde o final do século XIX existia uma carência de profissionais qualificados e professores que pudessem suprir essa mão de obra. Dentre as medidas oficiais para o enfrentamento desse problema está o Decreto $n^{0} 7.566$, de 23 de setembro de 1909, do então presidente da República Nilo Peçanha, que estabeleceu a criação das Escolas de Aprendizes e Artífices, vinculadas ao Ministério da Agricultura, Comércio e Indústria.

Apesar da intenção do governo da época de criar uma instituição modelar para o ensino profissionalizante, a Escola Normal de Artes e Ofícios Venceslau Brás acabou se tornando a única Escola Normal voltada para o Ensino Profissional até o seu fechamento em 1937 (CARDOSO, 2013). As atividades escolares da Venceslau Brás foram encerradas para que houvesse a demolição do prédio e a construção das novas instalações de um liceu, que não chegou a funcionar devido à demora da finalização da obra e à nova diretriz definida para o Ensino Industrial na década de 1940. Durante a gestão de Gustavo Capanema no Ministério da Educação e Saúde Pública (1934-1945) no governo Vargas, a reforma educacional implantada, da qual se pode destacar a Lei Orgânica do Ensino Industrial, traçou

\footnotetext{
${ }^{1}$ O levantamento das pesquisas foi realizado durante o período de 2013 a 2016.
} 
determinações para o Ensino Profissional Industrial na época.

Em 1942, no espaço da antiga instituição, foi criada a Escola Técnica Nacional (ETN) com a promulgação do Decreto $n^{\circ} 4.127$, de 25 de fevereiro de 1942, que estabelecia as bases de organização das instituições de Ensino Industrial da rede federal. Segundo o decreto, o objetivo das Escolas Técnicas passou a ser a formação para atender tanto aos interesses dos trabalhadores quanto aos interesses dos empresários industriais (BRANDÃO, 2009).

Em 1965, a ETN passou a se chamar Escola Técnica Federal da Guanabara (ETFGB) devido à transferência da capital do Brasil para Brasília. No ano seguinte, foi criado o curso de Engenharia de Operação em parceria com a Universidade Federal do Rio de Janeiro, que se responsabilizou pelo corpo docente e pela expedição de diplomas. Apesar de a mudança de nome parecer apenas vinculada à mudança da capital do país, percebe-se esse processo como uma tentativa de ruptura do vínculo entre o nome da escola e o governo Vargas.

A instituição foi renomeada mais uma vez, em 1967, e passou a se chamar Escola Técnica Federal Celso Suckow da Fonseca (ETFCSF) em homenagem póstuma a seu diretor, que contribuiu para a implementação, consolidação e desenvolvimento institucional do Ensino Técnico no país.

A Lei $n^{\circ}$ 6.545, de 30 de junho de 1978, dispôs sobre a transformação das Escolas Técnicas Federais em Centros de Educação Tecnológica Federal - CEFETs, com o intuito de verticalizar e promover a continuidade da formação industrial do Nível Médio ao Nível Superior. No caso do CEFET/RJ, o processo de adequação ao novo regimento, que mudou o status de Escola Técnica para instituição com Nível Superior, passando a atuar como autarquia vinculada ao Ministério de Educação e Cultura (MEC), durou quatro anos (SILVEIRA, 2006).

No início dos anos 1990, a educação tecnológica passou a ser concebida como uma educação moderna que promovia o acompanhamento do desenvolvimento de forças produtivas em relação estreita com a demanda de mercado (BRANDÃO, 2009). Durante a gestão do presidente da República Fernando Henrique Cardoso (1995-2003), houve a separação entre Ensino Médio e Ensino Profissional. No governo de Luís Inácio Lula da Silva (2004-2010), o decreto que dispôs sobre a separação do ensino foi revogado e permitiu-se que a Educação Profissional fosse oferecida de forma integrada, concomitante ou de forma sequencial, aos que já possuíssem o Ensino Médio.

Em dezembro de 2008 foram criados os Institutos Federais de Educação, Ciência e Tecnologia que surgiram a partir dos CEFETs, das escolas agrotécnicas e das escolas técnicas vinculadas a universidades. No entanto, o CEFET/RJ e o CEFET/MG já haviam iniciado o 
processo de solicitação junto ao MEC para sua transformação em universidade tecnológica, assim como ocorreu com o CEFET/PR, que foi transformado em Universidade Tecnológica Federal do Paraná (UTFPR), antes da lei de criação dos Institutos Federais.

Dentro desse escopo, o objetivo da nossa investigação foi analisar a disciplina de Matemática dos cursos industriais e técnicos da Escola Técnica Nacional no período de 1942 a 1964, para identificar as similaridades e as diferenças dessa disciplina em escolas de Ensino Industrial comparativamente ao Ensino Secundário da época.

\section{Aporte teórico-metodológico e fontes da pesquisa}

O estudo realizado neste artigo utilizou como aporte teórico-metodológico as ideias de André Chervel (1990) sobre a história das disciplinas escolares. O referido autor considera as disciplinas como criações espontâneas da escola, e não uma simples vulgarização de um saber científico. O conceito de disciplina inicialmente remete-nos aos conteúdos ou matérias e se caracteriza como "um modo de disciplinar o espírito e dar os métodos e regras para abordar os diferentes domínios do pensamento, do conhecimento e da arte" (CHERVEL, 1990, p. 180).

Os textos oficiais programáticos, discursos ministeriais, leis, decretos e programas apresentam as finalidades das disciplinas e, de acordo com Chervel (1990), devem ser a primeira documentação a ser analisada para identificar os objetivos, mas nem todas as finalidades estão inscritas nos textos destacados. Segundo o autor, ainda, deve-se questionar se as finalidades inscritas foram colocadas em prática no contexto escolar. Para isso, é necessária a utilização de uma dupla documentação: a dos objetivos fixados e a da realidade pedagógica. Assim, para realizar a pesquisa sobre a disciplina de Matemática na ETN utilizamos como fontes históricas: a legislação vigente sobre o Ensino Industrial e o Ensino Secundário na época investigada, além de documentos para a realização da disciplina que nos remetem a uma cultura escolar ${ }^{2}$, encontrados tanto no Setor de Arquivos do CEFET/RJ ${ }^{3}$ (SEARQ), quanto na Associação de Ex-Alunos do CEFET/RJ e da ETN (AEACEFETN).

Chervel (1990) afirma que os conteúdos são o ponto central das disciplinas escolares. Para realizar a análise dos documentos que fizeram parte da cultura escolar da ETN, observamos os seguintes conceitos desse autor, que considera como itens constitutivos da

\footnotetext{
${ }^{2}$ Consideramos como um "[...] conjunto de normas que definem conhecimento a ensinar e condutas a inculcar, e um conjunto de prática que permitem a transmissão desses conhecimentos e a incorporação desses comportamentos" (JULIA, 2001, p. 10).

${ }^{3}$ Segundo Cardoso (2013), seguem as tabelas de temporalidade do Arquivo Nacional. A investigação utilizou parte dos documentos referentes ao fundo da ETN.
} 
disciplina: a) o ensino de exposição - a forma como os conteúdos são transmitidos para os alunos, seja pela exposição do professor ou dos manuais didáticos; b) os exercícios - as atividades executadas pelos alunos, que podem ser observáveis pelos professores e utilizadas para a fixação dos conteúdos; c) as práticas de incitação e motivação - fazendo com que o conhecimento transmitido seja interessante para o corpo discente; e d) o aparelho docimológico - relacionado às avaliações dos alunos, seja em exames internos ou externos.

\section{A Matemática no Ensino Secundário}

Valente (2007) pesquisou a história do processo de escolarização da Matemática entre 1730 e 1930 no Brasil. Segundo o autor, os conteúdos matemáticos desenvolveram na ocasião uma Matemática escolar clássica, consolidada como um saber técnico relacionado à formação dos engenheiros para um saber da escola e de cultura geral, sendo lecionadas na época: Aritmética, Álgebra e Geometria.

Depois de 1930, Valente (2007) afirma que a Escola Nova influenciou a criação de uma nova Matemática escolar. Assim, a partir da Reforma Francisco Campos ${ }^{4}$, em 1931, as três áreas de Matemática foram unificadas em uma única disciplina, sendo essa reforma responsável pelo processo de organização do Ensino Secundário em nível nacional, dividindo o curso secundário em dois ciclos: Fundamental e Complementar. Posteriormente, em 1942, foi realizada uma nova reforma educacional por Gustavo Capanema, o Ministro da Educação e Saúde Pública da época, resultando em ajustes nos dois ciclos do curso secundário. $\mathrm{O}$ primeiro ciclo passou a ter quatro séries e o segundo, além de perder o caráter preparatório, sofreu modificações na quantidade de séries, ficando conhecido como colégio, que se dividia em dois cursos: o Clássico e o Científico.

Valente (2011) destaca que, após a década de 1930, a Matemática Escolar no Brasil desenvolvida no Ensino Secundário teve processos diferentes na sua trajetória e com isso resultou em duas disciplinas: a Matemática do ginásio e a Matemática do colégio.

A Matemática do ginásio teve sua origem no primeiro movimento internacional de ensino da Matemática. O projeto para a disciplina, de acordo com a Reforma Francisco Campos, foi apresentado pelo professor Euclides Roxo para o Colégio Pedro II, onde era professor e depois assumiu o cargo de diretor, baseando-se em propostas concebidas pelo

\footnotetext{
${ }^{4}$ Primeira reforma educacional realizada, no início da Era Vargas, pelo Ministro da Educação e Saúde Pública (MESP) Francisco Campos [1891-1968]. Tal reforma foi responsável por dar maior organização à estrutura educacional do país, especialmente do ensino secundário, comercial e superior.
} 
matemático Félix Klein. Entre as principais ideias, estava a unificação dos três ramos da Matemática em torno do conceito de Função. Havia três tendências: metodologia, seleção de doutrina e finalidades. Além dos conteúdos, foram expedidas Instruções Metodológicas para a Reforma Francisco Campos. Assim, os conteúdos foram divididos em áreas (Iniciação Geométrica, Aritmética e Álgebra) ao longo das cinco séries do curso Fundamental e as instruções enfatizavam o desenvolvimento do espírito e raciocínio lógico.

A Matemática do colégio teve um processo de constituição diferente da Matemática do ginásio, uma vez que não se deu por um processo de continuidade, surgindo a partir dos Cursos Complementares que eram divididos em pré-jurídico, pré-médico e pré-politécnico. Os conteúdos para esses cursos não eram padronizados e como havia uma grande diferença entre assuntos e cobranças nas provas de acesso ao Ensino Superior, os cursos apresentavam uma lista com matérias a serem estudadas pelos alunos. Isso fez com que surgissem vários livros didáticos para cada assunto, o que facilitou o advento de um expressivo número de autores desses manuais. Após a Reforma Capanema, o colégio inicia um processo de padronização de conteúdos e métodos de ensino, havendo, inicialmente, diferença entre os assuntos dos cursos Clássico e Científico, bem como em sua carga horária.

\section{A Matemática no Ensino Industrial}

O Decreto $n^{\mathrm{o}}$ 7.566, de 23 de setembro de 1909, do presidente Nilo Peçanha, foi um marco importante para o Ensino Industrial brasileiro. Schwartzman, Bomeny e Costa (2001) afirmam que tal ação tinha como finalidade a redução dos problemas sociais, advindos da urbanização que se iniciava no país. Após a Revolução de 1930, as forças políticas no governo passaram a valorizar a indústria como a atividade econômica mais importante para gerar progresso em diferentes níveis. Brandão (2009, p. 6-7) considera que houve um “[...] processo de mudança na sua função [das escolas técnicas] de solução de problemas urbanos à formação de uma mão de obra para subsidiar o projeto de desenvolvimento capitalista no país".

Durante a gestão de Gustavo Capanema no Ministério da Educação e Saúde Pública (1934-1945), no governo de Getúlio Vargas, foi implantada uma grande reforma educacional. Dentre as principais ações, destacamos a Lei Orgânica do Ensino Industrial ${ }^{5}$, que tinha como foco a formação de profissionais para atuar na indústria, promover qualificação profissional aos jovens e adultos não diplomados ou habilitados, aperfeiçoar ou especializar os

\footnotetext{
${ }^{5}$ Decreto-lei no 4.073, de 30 de janeiro de 1942.
} 
trabalhadores diplomados e divulgar conhecimentos de atualidades técnicas (BRASIL, 1942b).

O Ensino Industrial estava dividido em dois ciclos, assim como o Ensino Secundário: no primeiro ciclo era oferecido o curso industrial básico, com duração de quatro anos, que tinha equivalência com o ginásio; no segundo, ofertava-se o curso técnico com duração de três anos, sendo equivalente ao colégio.

Os cursos do Ensino Industrial tinham dois tipos de disciplinas: de cultura geral e de cultura técnica, além das práticas educativas (educação física, educação musical, educação pré-militar, educação doméstica). De acordo com a Lei Orgânica, as disciplinas de cultura geral e as práticas educativas deveriam acentuar e elevar o valor humano do trabalhador. Ademais, seriam organizados periodicamente e revistos os programas, que deveriam conter um sumário com os conteúdos e a indicação dos métodos e dos processos pedagógicos adequados (BRASIL, 1942b).

A distribuição das disciplinas de cultura geral do curso industrial básico colocava a disciplina de Matemática em todas as séries dos cursos, com uma carga horária de três horas semanais (BRASIL, 1943). Percebemos, comparando esse curso com o ginásio, que tinham semelhanças no que tange à presença da disciplina nas quatro séries e à carga horária.

A grade curricular das disciplinas de cultura geral dos cursos técnicos tinha a disciplina de Matemática apenas na $1^{\text {a }}$ série, com uma carga horária de cinco horas semanais (BRASIL, 1943). Adicionalmente, entre as disciplinas de cultura técnica, encontramos a disciplina Complementos de Matemática, que era oferecida apenas em alguns cursos técnicos. Esse fato nos permite abrir uma discussão sobre a Matemática como um conhecimento que estava ligado à cultura geral e à cultura técnica no Ensino Industrial.

Identificamos alguns indícios de que tal disciplina não era a mesma que a Matemática do ginásio e a Matemática do colégio. Como sinalizado por Chervel (1990), para caracterizar uma disciplina, além de analisar os objetivos estabelecidos, devemos investigar a prática pedagógica para identificar se esses objetivos foram colocados em prática ou não. Desse modo, observamos, a partir da legislação, que a Matemática do Curso Industrial básico tinha similaridades com a Matemática do ginásio, no que se refere aos conteúdos e a sua forma de organização. Já no que concerne à Matemática dos cursos técnicos, verificamos que havia diferenças com a Matemática do colégio, como a organização, a carga horária e a distribuição ao longo das séries, além da questão da dualidade da natureza desta disciplina. 


\section{A Matemática nos documentos escolares da ETN}

No setor de arquivos do CEFET/RJ, encontramos relatórios, diários, horários das disciplinas, livros, apostilas, fichas de aluno, fichas de professores, livro de assentamento e provas. Para a nossa análise, utilizamos relatórios, livros, apostilas e provas.

No relatório de 1946 da ETN, identificamos: a) um programa de Matemática para os Cursos Industriais básicos; b) um programa de Matemática para os Cursos Técnicos; c) um programa de Complementos de Matemática para Cursos Técnicos e d) um programa de Matemática e Complementos de Matemática para o Curso Técnico de Construção Aeronáutica.

O programa de Matemática para os Cursos Industriais básicos foi chancelado pelo professor José Ernani de Lima, sendo, de acordo com o Relatório de 1946, uma adequação de uma proposta enviada pela Divisão de Ensino Industrial (DEI), pois os professores da instituição consideraram que a proposição continha itens repetitivos, cujos assuntos necessitavam de revisão ao longo das séries, o que despendia muito tempo. No programa da ETN, averiguamos que havia divisão dos conteúdos entre as áreas de Aritmética, Álgebra e Geometria e Trigonometria.

Ao compararmos o referido programa da ETN com o programa do curso ginasial da Reforma Capanema, percebemos similaridades nos conteúdos e na sua distribuição ao longo das séries. Entre os itens que estavam em ordem diferente, havia a temática de sistemas métricos, que, no programa da ETN, era apresentada a partir da $1^{a}$ série, o que fazia sentido pela necessidade de mensuração nos Cursos Industriais, diferentemente da que era apresentada no programa do ginásio. Por sua vez, a temática de Trigonometria, que fazia parte do programa apresentado na escola na $4^{\mathrm{a}}$ série, não estava presente no programa do Ensino Secundário.

Também analisamos e comparamos esse programa da ETN com o Programa Mínimo apresentado, em 1951, para o ginásio. Os conteúdos desse segundo programa eram parecidos com os do programa da Reforma Capanema, entretanto sua distribuição era diferente, sem a divisão por áreas. Desse modo, ao compararmos o programa da escola com o do Programa Mínimo de 1951, notamos diferenças na distribuição dos conteúdos, com exceção da $1^{\text {a }}$ série. Observamos que a Trigonometria era uma constante nos programas e que a questão relacionada à metrologia de todos os programas estava inserida desde a $1^{\mathrm{a}}$ série, como também a valorização da Geometria. Verificamos também que os programas já apresentavam conteúdos de Álgebra desde a $2^{\text {a }}$ série, o que era diferente do programa da ETN, que inseria a 
temática apenas a partir da $3^{\mathrm{a}}$ série.

Os cursos técnicos de eletrotécnica, desenho técnico, edificações e decoração de interiores tinham o mesmo programa de Matemática na ETN. Além disso, os cursos de eletrotécnica, edificações e construções de máquinas e motores, que ofereciam Complementos de Matemática, tinham um programa para a disciplina. Com relação ao curso de Construção Aeronáutica, havia um único programa que contemplava tanto Matemática quanto Complementos de Matemática. A organização dos dois programas foi realizada pelo professor João Dias dos Santos Júnior da ETN, ocorrendo as disciplinas de Matemática e de Complementos de Matemática, como já citado, somente na $1^{\mathrm{a}}$ série dos Cursos Técnicos.

Ao compararmos o programa de Matemática dos Cursos Técnicos com os programas apresentados para os cursos Científico e Clássico, tanto da Reforma Capanema quanto do Programa Mínimo de 1951, percebemos diferenças nos conteúdos, especialmente os não contemplados no programa da ETN, como áreas que sequer apresentavam quaisquer conteúdos, (como as de Aritmética Teórica, Geometria Plana, Geometria Espacial e Geometria Analítica) e alguns conteúdos explícitos como Polinômios e Cônicas que não faziam parte da grade.

No programa da disciplina Complementos de Matemática, todos os conteúdos constavam nos programas do colégio de 1943 e 1951; no entanto, como já mencionamos, essa disciplina não era oferecida para todos os Cursos Técnicos, não existindo uniformidade entre os mesmos no que tange aos conteúdos matemáticos ensinados. A disciplina era de Cultura Técnica, com ênfase em Cálculo Vetorial e em Geometria Analítica. Dessa forma, ainda que somássemos os conteúdos da disciplina de Matemática e de Complementos de Matemática, não teríamos os mesmos conteúdos explícitos do colégio.

O programa de Matemática e Complementos de Matemática do curso de Construção Aeronáutica era apresentado como um único programa para as duas disciplinas, ou seja, havia diferença na estrutura do programa para esse curso com relação aos demais cursos. Além disso, inicialmente, o corpo docente desse curso não fazia parte da instituição. O programa possuía conteúdos mais próximos aos dos cursos Científico e Clássico do que o programa dos outros cursos técnicos. Todavia, notamos que o programa não contemplava todos os conteúdos do colégio. Assim, assuntos como Seç̧ões Cônicas, por exemplo, não apareciam nesse programa da Escola e os conteúdos estavam divididos em Revisão de Aritmética e Álgebra, Álgebra, Geometria Plana, Geometria Espacial, Régua de Cálculo e Trigonometria. Não encontramos outras informações além dessas sobre essa disciplina no âmbito dos arquivos da ETN, devido ao fato de a disciplina ter sido oferecida por um escritório 
contratado para lecionar as aulas.

A partir de 1959, a escola ganhou maior autonomia com o Decreto $\mathrm{n}^{\circ} 47.038$, de 16 de outubro de 1959. Por conseguinte, as decisões sobre a disciplina de Matemática ganham maior liberdade, passando em parte pelo Conselho de Representantes e pelo Conselho de Professores. Assim, encontramos no arquivo do CEFET/RJ uma proposta de programa, sugerindo que a disciplina de Matemática para os Cursos Técnicos fosse oferecida em duas séries (ESCOLA TÉCNICA NACIONAL, 1964). A partir de 1964, constatamos que não havia mais distinção entre os Cursos Técnicos e o programa era único para todos os Cursos Técnicos da escola. Dessa maneira, havia apenas uma única disciplina, sendo que Complementos de Matemática não fazia mais parte da grade de disciplinas técnicas oferecidas e, aparentemente, quase todos os conteúdos foram assimilados pela nova disciplina de Matemática, com exceção de Cálculo Vetorial.

Os conteúdos apresentados no programa de 1964 da ETN estavam inseridos no programa do colégio, no entanto não representavam a totalidade de assuntos abordados nos programas do Clássico e Científico. Desse modo, havia os que não estavam inseridos nesse programa, como alguns de Geometria Plana e de Geometria Espacial (como, por exemplo, Retas e Planos). A proposta apresentada nesse programa estaria em conformidade com o que Cunha (1980) afirma em relação aos cursos secundários e técnicos: que se aproximaram na constituição de um único Ensino Secundário. Contudo, no programa da ETN, percebemos que a Matemática ainda não estava presente nas três séries, bem como a quantidade de aulas também acabava por ser diferente.

\section{Apostilas e livros de Matemática da ETN}

Os manuais didáticos têm uma grande importância dentro da ETN. Para determinar essa importância, procuramos por cadernos e, em conversas informais com os ex-alunos da AEACEFTN, constatamos que eles utilizavam apostilas ou livro. Tais materiais utilizados podem ter sido uma vulgata, que, na visão de Chervel (1990), é um produto da constituição da disciplina, formando um padrão de referência para os livros didáticos e norteando as produções didáticas de um período quando a disciplina passa pelo processo de estabilização.

Inicialmente, os alunos recebiam apostilas de Matemática confeccionadas pela instituição por meio do curso de tipografia, cuja distribuição ocorreu depois do ano de 1945, com o ingresso do professor e autor Arlindo Clemente na instituição. Em seguida, houve financiamento pela Comissão Brasileira Americana de Educação Industrial (CBAI) para a 
produção de livros destinados às Escolas Técnicas, inclusive a própria ETN. Tais manuais foram distribuídos gratuitamente para os alunos dos Cursos Industriais básicos e dos Cursos Técnicos a partir de 1951.

Em uma visita ao SEARQ do CEFET/RJ, encontramos duas apostilas e dois livros que foram utilizados no período da ETN para os Cursos Industriais básicos e, ainda, uma apostila de Trigonometria que foi adotada para os Cursos Técnicos. Localizamos, também, em sebos virtuais, a coleção Caderno de Matemática do Curso Industrial básico, a coleção Matemática para Cursos Técnicos e a coleção Matemática ${ }^{6}$.

O professor Arlindo Clemente firmou-se como autor dos manuais da disciplina adotados pela ETN. Em uma reflexão sobre os livros didáticos para o Ensino Industrial, ele declara:

\begin{abstract}
Bibliografia lamentavelmente pobre é a nossa. Nem livros textos, nem de exercícios. Nossos programas essencialmente diferentes dos programas ginasiais e sobretudo nossos alunos, em números e capacidade aquisitiva, consideravelmente menores, não tem atraído os autores nacionais à elaboração de livros que resolveriam poucas dificuldades. Já estamos tentando solucionar o problema. Confeccionamos apostilas com a parte teórica de nossos programas. São o arcabouço de uma obra que pretendemos, em futuro próximo, completar e oferecer aos nossos alunos (CLEMENTE, 1948, p. 86).
\end{abstract}

A partir desse texto, compreendemos como as apostilas adotadas na ETN originaram os manuais didáticos, que, posteriormente, foram publicados para os Cursos Industriais no país com o apoio da CBAI. Nesse mesmo trecho, o autor nos elucida sua concepção sobre a questão de a disciplina de Matemática do Ensino Industrial ser diferente da disciplina do Ensino Secundário, o que concluímos ser uma visão parcial do autor, pois havia similaridades, como estamos evidenciando neste trabalho.

A coleção Caderno de Matemática possui quatro livros destinados para as séries dos Cursos Industriais básicos. Verificamos que tal coleção foi baseada nas apostilas elaboradas e tipografadas na própria ETN.

Entre os materiais didáticos utilizados nos Cursos Técnicos, encontramos apenas uma apostila da disciplina sobre Trigonometria e uma coleção de livros em dois volumes. Esses conteúdos estavam de acordo com o programa de Matemática de 1946 para Trigonometria, não havendo nenhuma mudança no programa, que seguia exatamente o que estava fixado nos objetivos.

A coleção de Matemática para os Cursos Industriais Técnicos foi difundida pela ETN.

\footnotetext{
${ }^{6}$ Tal coleção apresentava os mesmos conteúdos e exercícios da coleção Matemática para Cursos Técnicos, mas foi publicada por outra editora.
} 
Os volumes foram publicados em anos diferentes, sendo o primeiro em 1965 e o segundo em 1966. Constatamos que esse material, na temática de Trigonometria, baseou-se na apostila de 1952, com conteúdos e exercícios sendo praticamente os mesmos. Como o autor produziu outros materiais para o Nível Médio, apesar de não localizados, inferimos que os reaproveitou na elaboração dessa obra.

\section{Os itens constitutivos da disciplina de Matemática na ETN}

Neste item analisamos os materiais didáticos a partir dos quatro itens constitutivos elencados por Chervel (1990): a) exposição de conteúdos; b) exercícios; c) práticas de incitação e motivação e d) aparelho docimológico.

Com relação à exposição de conteúdos nos manuais didáticos da ETN, observamos que tal exposição dava-se basicamente pela introdução direta da temática e pela apresentação de definições, teoremas ou explicações, seguidas por um exemplo e, posteriormente, por exercícios. Ao compararmos as coleções expostas neste trabalho com os manuais adotados no Ensino Secundário, percebemos que a exposição de conteúdos no material da ETN apresentava-se de forma mais sucinta e direta; já os livros do ginásio e do colégio ${ }^{7}$ destinavam aos conteúdos um número maior de páginas para as explicações. Dessa forma, apresentavam de modo mais amplo os assuntos com um número maior de exemplos, sendo possível perceber diferença entre o número de páginas dedicadas aos livros do Ensino Secundário com relação às do Ensino Industrial.

Arlindo Clemente, em sua exposição no III Congresso de Ensino de Matemática, afirma que os alunos dos Cursos Industriais ficavam em tempo integral na escola, reduzindo o tempo dedicado aos estudos em casa; ainda ressalta que, como na escola esses alunos tinham as disciplinas de cultura geral e cultura técnica e as oficinas que demandavam grande tempo de dedicação, deveria haver uma adequação desses conteúdos à rotina escolar discente (MINISTÉRIO DA EDUCAÇÃO E CULTURA, 1959).

Amorim (2004) ressalta que a CBAI influenciou a formação de professores para o Ensino Industrial por meio da Racionalização Científica, que, segundo o autor, era caracterizada por procedimentos tayloristas, realizando, assim, adaptações do trabalho fabril para o ambiente escolar e sendo, dessa forma, responsável pela conformação de uma

\footnotetext{
${ }^{7}$ Fizemos uma análise a partir de: Coleção Elementos de Matemática, de Jácomo Stavale; Coleção Matemática, de Ary Quintela; Coleção Matemática Ginasial, dos quatro autores (Euclides Roxo, Haroldo Lisboa da Cunha, Roberto Peixoto e Cesar Dacorso Netto).
} 
"aristocracia do trabalho" - educada para atender à demanda no setor industrial em expansão no período compreendido entre o fim do Estado Novo e o início da década de 1960.

Um editorial da CBAI manifesta que se deveria buscar ajustar o homem à máquina, dando-lhe meios para que se habilitasse para dominar seu invento, de forma a obter maior rendimento com mínimo esforço. Esse trecho se enquadra nos dizeres que o professor Arlindo colocava em seus manuais didáticos: que visavam diminuir o esforço mecânico dos alunos para maior rendimento intelectual, o que significava para ele maior eficiência para estudar, realizar os exercícios. O referido professor foi autor de livros pela CBAI e recebeu formação dentro dos moldes planejados pela comissão.

Amorim (2004) realça que, analisando a produção de boletins e livros da CBAI, podiase ter uma noção da formação docente preconizada pela comissão, que concebia a atividade docente comparada à de um operário. Dessa maneira, a docência dos Cursos Industriais deveria seguir o modelo do trabalho fabril e se aproximar da indústria para a formação dos futuros profissionais. Com isso, os docentes deveriam aprender a lecionar de modo mais eficiente, ensinando no menor tempo possível com o mínimo de gasto de energia, tanto para o professor como para o aluno. Um dos princípios básicos seria o de que o "aluno só aprende a partir da necessidade que ele tenha de certo conhecimento, determinada pela exigência do ofício que esteja aprendendo" (AMORIM, 2004, p. 2). Como percebemos, tratava-se de uma concepção utilitária da educação, em que só interessava aquilo que estivesse ligado à futura ocupação profissional do aluno. Os demais itens estavam relacionados especificamente a questões didáticas, tais como a aprendizagem por meio da execução de tarefas práticas, as quais seriam ensinadas após a apresentação da parte teórica ou de forma simultânea. Da mesma maneira, na explicação aos alunos seriam utilizados analogias e exemplos conhecidos e uma linguagem mais clara e objetiva possível. Isso está de acordo com o material produzido pelo professor Arlindo, cuja linguagem era clara, com a explicação realizada de forma direta, sem muitos rodeios e sem muitas exceções, indo da definição à aplicação em um exemplo.

De acordo com Amorim (2004), as aulas para os Cursos Industriais deveriam ser do tipo prático-teórica, combinando o ensino de operações de um ofício com a teoria correspondente; ainda, deveriam apresentar as operações a serem realizadas na forma de uma "receita de bolo", ou seja, ensinando todos os passos para a realização de uma tarefa nas aulas. Isso se enquadrou nos materiais criados como modelos a serem seguidos por outras Escolas Técnicas, inicialmente com aval da CBAI e, depois, com a produção dos livros didáticos pela editora da ETN. Até mesmo os planos de aulas produzidos indicavam uma maneira de ensinar os conteúdos dessa forma no livro da Coleção para os cursos técnicos. 
Ainda, de acordo com o referido autor, na exposição de conteúdos, segundo o modelo apresentado pela CBAI, os assuntos deveriam ser tratados em sua totalidade, contendo elementos novos e conteúdos suficientes para prender a atenção dos alunos, bem como se relacionarem às experiências prévias dos educandos. Ademais, as aulas deveriam seguir os seguintes passos: introdução, apresentação do assunto, verificação e aplicação.

Tanto o material dos Cursos Industriais básicos quanto o do Técnico seguiam essa proposta de modelo, pois, mesmo em períodos diferentes, percebemos que foi mantida a forma de expor os assuntos pelo autor. Assim, observamos que pode ter havido estabilidade no processo, nos conteúdos e nos métodos de ensino utilizados nos livros durante o período em que os materiais foram produzidos, por conta da evolução das apostilas para uma coleção dos cursos da ETN. Por isso, afirmamos que o Caderno de Matemática e a coleção Matemática para Cursos Industriais têm fortes indícios de que se configuraram em vulgatas para o Ensino Industrial, diferentemente daqueles preconizados para a Matemática do ginásio e do colégio.

Os exercícios propostos no Ensino Industrial, especialmente na ETN, estavam presentes nos manuais didáticos produzidos pelo professor da instituição. A partir desses materiais, analisamos as características dos exercícios e como eram realizados.

Para Chervel (1990), sem os exercícios não seria possível fixar os assuntos, sendo o sucesso das disciplinas condicionado à qualidade das atividades propostas. Dessa forma, o autor confere uma posição privilegiada aos exercícios de uma disciplina, considerando-os uma peça fundamental para definir o sucesso ou o insucesso da disciplina.

Classificamos os exercícios encontrados nos livros didáticos utilizados na ETN em três tipos: exercícios diretos, problemas gerais e problemas aplicados. Os exercícios diretos eram atividades com um único comando, como calcular, determinar etc. Nesses exercícios, os alunos deveriam aplicar fórmulas, processos que foram apresentados na exposição, para a realização das respostas. Os problemas gerais eram exercícios que dependiam da interpretação para a resolução, ou até mesmo da realização de mais de uma operação para sua resolução. Nesse tipo de atividade, o aluno precisava interpretar o que estava descrito, realizar algumas operações e, então, resolver o problema proposto com algum método anteriormente apresentado nos materiais didáticos. Os problemas aplicados eram exercícios na forma de problemas que envolviam algum tipo de conhecimentos dos Cursos Industriais básicos, estando separados por trabalhos gráficos, de mecânica, de eletricidade e de agulhas. Observamos que, além de procedimentos para a resolução - apresentados na exposição, informações e contexto -, havia a introdução de nomenclatura relacionada à futura profissão 
do aluno.

Clemente (1948) comenta que a escolha dos problemas de aplicação residia na diferença entre a modalidade de Ensino Secundário e de Ensino Industrial, já que a Matemática no Ensino Industrial deveria estar relacionada com a oficina.

No material do Curso Industrial básico, os exercícios aplicados concentravam-se em sua maior parte nos volumes 1 e 2 da coleção Caderno de Matemática. Isso poderia estar associado ao nível de maturidade exigido para as outras séries em que estavam sendo desenvolvidas a Geometria Dedutiva e a Álgebra. Apesar da similaridade de conteúdos com o ginásio, notamos que os exercícios não seguiam a mesma ordem, nem o mesmo tipo, divergindo em sua quantidade - a qual era bem limitada nos livros do Ensino Industrial, se comparada com o Ensino Secundário.

Como exemplo das diferenças entre os dois tipos de material, citamos o caso das operações básicas, pois era comum encontrar nos manuais do ginásio exercícios diretos que envolvessem contas de adição, subtração, multiplicação ou divisão; já, no caso do manual da ETN para os Cursos Industriais, eram adotados apenas problemas. Essa variação não ocorria apenas para esse tipo de conteúdo. Como exemplo, a Geometria do volume 1 do Caderno de Matemática não possuía exercícios; no entanto, nos livros para o ginásio, apareciam vários; assim, também, não aparecem no similar do Ensino Industrial as demonstrações de Geometria, item exigido como exercício nos materiais do ginásio.

O ensino de uma disciplina não se constitui apenas pela exposição dos conteúdos e exercícios, importando também as práticas de incitação e motivação no processo de constituição dessa disciplina, de acordo com Chervel (1990, p. 205)

Conteúdos explícitos e a bateria de exercícios constituem então o núcleo da disciplina. Dois outros elementos vêm se acrescentar aí, todos os dois essenciais ao bom funcionamento, e aliás intimamente ligados aos precedentes. Nada se passaria em aula se o aluno não demonstrasse um gosto, uma tendência, disposições para os conteúdos e os exercícios que se lhe propõem.

Avaliando os materiais didáticos produzidos na ETN, identificamos que, para a motivação, foram utilizados, especialmente nos Cursos Industriais, problemas relacionados às áreas de atuação às quais o aluno poderia estar vinculado. Assim, o fato de ter sido construído um material específico para o Ensino Industrial demonstra uma preocupação de não apenas utilizar os materiais existentes, e sim de adequar os manuais para a modalidade de ensino. Apesar de os conteúdos estarem na gama de assuntos propostos para o Ensino Secundário, houve necessidade de adequar os materiais - que se destacaram pela exposição clara e sucinta dos assuntos, como já apresentamos - com exercícios, que poderiam ser aplicados ou não, e 
com a utilização de problemas.

A ideia das propostas implementadas pela CBAI para a formação docente levava em conta a questão motivacional dos alunos, pois

\begin{abstract}
Havia uma preocupação toda especial com a motivação para a aprendizagem. Para tanto o professor deveria fazer experiências reais, aplicar na prática as teorias aprendidas, empregar condições de trabalho reais na sala de aula, utilizar auxílios visuais, organizar projetos e verificar a aprendizagem dos alunos (AMORIM, 2004, p. 3).
\end{abstract}

Analisando a produção do professor Arlindo para a CBAI, notamos que seguia as ideias propostas pela Racionalização Científica, considerando essencial a formação docente especializada no ramo industrial. Toda a questão das práticas de motivação e incitação para o ensino da ETN estava presente em vários itens da disciplina, que, de acordo com Chervel (1990, p. 205)

Trata-se não somente de preparar o aluno para a nova disciplina, mas de selecionar, aliás com igual peso, os conteúdos, os textos, as narrações mais estimulantes na verdade de levar-lhe a se engajar espontaneamente nos exercícios nos quais ele poderá expressar sua personalidade.

Com isso, percebemos que o processo de seleção dos conteúdos, a exposição e os exercícios encontrados nos manuais didáticos da ETN eram estratégias de práticas de motivação e incitação.

Conforme conceituado por Chervel (1990), o aparelho docimológico, que se relaciona com a avaliação realizada na instituição, faz parte dos itens constituintes da disciplina.

No Ensino Industrial, a Lei Orgânica de 1942, no art. 43, preconizava que, para cada disciplina, seriam aplicados dois tipos de exames: os primeiros exames, realizados na primeira quinzena de junho, que poderiam ser uma prova escrita, gráfica ou prática; e exames finais, objetivando a promoção à série escolar imediata ou a conclusão do curso, que deveriam ser escritos, gráficos ou orais.

O relatório de 1946 da ETN apresentava informações sobre modificações no processo de avaliação, que foi estabelecido pelo Decreto $n^{0}$ 9.498, de 22 de julho de 1946: a obrigatoriedade de duas provas parciais, que poderiam ser escritas ou gráficas, além do exame final, que poderia ser uma prova oral ou gráfica (ESCOLA TÉCNICA NACIONAL, 1946).

Foram encontradas quatro avaliações no arquivo do CEFET/RJ, as quais eram destinadas aos Cursos Técnicos e, de acordo com o plano de curso, deveriam ocorrer mensalmente. Ao analisarmos essas avaliações, percebemos que seguiam o modelo de exercícios diretos dos manuais didáticos.

Três provas mensais apresentavam cinco questões discursivas; na quarta prova, havia cinco questões discursivas e uma questão para completar as informações. 
Em três provas encontradas, havia questões de Trigonometria; na outra prova, além dessa temática, havia questões relacionadas à Geometria Espacial e a Progressões.

As provas relacionadas eram baseadas em exercícios diretos, mas a prova que continha itens de Geometria Espacial apresentava questões em forma de problemas.

Ainda, nesse contexto, como não encontramos provas anteriores a 1960 e dos cursos industriais, não pudemos verificar se eram utilizados problemas aplicados à oficina.

Apesar dos aspectos que as aproximam dos materiais utilizados na ETN, percebemos que as provas têm características comuns àquelas utilizadas no Ensino Secundário, talvez devido ao fato de que as avaliações encontradas no SEARQ sejam datadas da década de 1960 e, em tal período, segundo Cunha (1980), o ensino técnico sofreu um processo de secundarização.

\section{Considerações finais}

A partir da análise dos vestígios históricos como relatórios, planos de cursos, horários e diários, verificamos que a disciplina na ETN seguia as determinações da Lei Orgânica de 1942 e das portarias que foram promulgadas para regulamentação dos cursos.

Nos Cursos Industriais básicos era ofertada a disciplina de Matemática, dentro de cultura geral, com carga horária de três horas semanais, a respeito da qual encontramos apenas um único programa que descrevia os conteúdos. Notamos similaridades entre os conteúdos e a estrutura dessa disciplina com os da disciplina do ginásio.

Nos Cursos Técnicos, verificamos que não havia uniformidade nos conteúdos matemáticos, visto que ofereciam três conformações possíveis: a) apenas a disciplina de Matemática; b) as disciplinas de Matemática e de Complementos de Matemática e c) as disciplinas de Matemática e Complementos de Matemática de forma específica para o curso de Construção Aeronáutica, que possuía programas e professores diferentes. Após 1960, a Matemática dos Cursos Técnicos passou a ser única para todos os cursos, contribuindo para uma padronização de conteúdos e métodos de ensino.

Ao analisarmos os problemas iniciais definidos por Chervel (1990) no estudo de uma disciplina, em relação à sua função, percebemos que, em parte, estava afinada com o objetivo do Ensino Industrial de ser aplicada à oficina. No que diz respeito ao seu funcionamento, identificamos que livros e apostilas eram utilizados como material didático assim como a avaliação realizada inicialmente era composta por duas provas, posteriormente modificandose para provas parciais que deveriam ocorrer mensalmente. 
$\mathrm{Na}$ análise dos manuais didáticos constatamos que eles possuíam características próprias: explicavam os conteúdos por meio de uma introdução, que utilizava definições, teoremas e explicações, seguidas por exemplos; na sequência, havia exercícios, que estavam separados em três tipos: diretos, problemas gerais e problemas específicos (apenas nos Cursos Industriais básicos). Inferimos, então, que parte das características desse material era comum a qualquer livro didático de Matemática.

Identificamos, ainda, que a Matemática da ETN foi uma representação da disciplina voltada para os cursos e, por isso, houve necessidade de criação de materiais próprios, mas, como relatamos, havia similaridades com o Ensino Secundário e isso se deveu ao fato de essa representação ter se constituído em apropriações da disciplina do ginásio e do colégio.

\section{Referências}

ALVAREZ, T. G. A Matemática da Reforma Francisco Campos em ação no cotidiano escolar. 2004. 257 f. Dissertação (Mestrado em Educação Matemática) - Programa de Estudos Pós-graduados em Educação Matemática, Pontifícia Universidade Católica de São Paulo, São Paulo, 2004.

AMORIM, M. L. "O máximo de rendimento com o mínimo de esforço": a introdução de métodos de trabalho racionais nas escolas técnicas e industriais mediante as publicações da Comissão BrasileiroAmericana de Educação Industrial (CBAI). In: CONGRESSO BRASILEIRO DE HISTÓRIA DE EDUCAÇÃO, 3., 2004, Curitiba. Anais... Curitiba: Champagnat, 2004. p.1-12.

BRANDÃO, M. CEFET Celso Suckow e algumas transformações históricas na formação profissional. Trabalho Necessário, Nitéroi, v. 7, n. 9, p. 1-22, 2009. Disponível em: https://periodicos.uff.br/trabalhonecessario/article/view/6099/5064. Acesso em: 20 mar. 2014.

BRASIL. Decreto-lei $\mathbf{n}^{0}$ 4.127, de 25 de fevereiro de 1942. Estabelece as bases de organização da rede federal de estabelecimentos de ensino industrial. Diário Oficial da União, Rio de Janeiro, DF, 27 fev. 1942a. n. 48, Seção 1, p. 2957-2958.

Ministério da Educação e Saúde. Decreto-lei no 4.073, de 30 de janeiro de 1942. Lei Orgânica do Ensino Industrial. Diário Oficial da União, Rio de Janeiro, DF, 9 fev. 1942b. n. 33, Seção 1, p. 1997-2002.

Ministério da Educação e Saúde. Portaria Ministerial n 169, de 13 de março de 1943. Dispõe sobre a limitação e distribuição de tempo dos trabalhos escolares no ensino industrial e dá outras providências. Diário Oficial da União, Capital Federal, 15 mar. 1943, n. 61, Seção 1, p. 37303731.

CARDOSO, T. F. L. Um acervo da memória nacional: o arquivo do CEFET/RJ. In: NASCIMENTO, A.; CHAMON, C. (org.). Arquivos e História do Ensino Técnico no Brasil. Belo Horizonte: Mazza Edições, 2013. v. 1, p. 105-120.

CHERVEL, A. História das disciplinas escolares: reflexões sobre um campo de pesquisa. Teoria $\boldsymbol{\&}$ Educação, Porto Alegre, v. s/n, n. 2, p. 177-229, 1990.

CLEMENTE, A. Sôbre o ensino da matemática nas escolas de ensino industrial. BOLETIM DO

CBAI, Rio de Janeiro, v. 2, n. 4, p. 86-87, 1948. 
CUNHA, L. A. "Ensino secundário e ensino industrial: Análise da influência recíproca”. Síntese, Rio de Janeiro, v. 7, n. 18, p. 49-71, jan./abr. 1980.

DASSIE, B. A. A Matemática do curso secundário na reforma Gustavo Capanema. 2001. $170 \mathrm{f}$. Dissertação (Mestrado em Matemática) - Departamento de Matemática da Pontifícia Universidade Católica do Rio de Janeiro, Rio de Janeiro, 2001.

ESCOLA TÉCNICA NACIONAL. Conselho de Professores. Ata do Conselho de Professores do dia 23 de janeiro de 1964. Arquivo do CEFET/RJ, Caixa 62.4.3, pasta ETN1.01.001. p.1-15

ESCOLA TÉCNICA NACIONAL. Relatório de 1946. Rio de Janeiro: Gráfica da ETN, 1946.

JULIA, D. A cultura escolar como objeto histórico. Revista Brasileira de História da Educação, Campinas, v.1, n. 1, pp. 9-44, 2001.

MARQUES, A. S. Tempos pré-modernos: a matemática escolar dos anos 1950. 2005. 150 f. Dissertação (Mestrado em Educação Matemática) - Programa de Estudos Pós-Graduados em Educação Matemática, Pontifícia Universidade Católica de São Paulo, São Paulo, 2005.

MOURA, E. C. M. O ensino de matemática na Escola Industrial de Cuiabá/MT no período de 1942 a 1968. 2012. 127 f. Dissertação (Mestrado em Educação Matemática) - Instituto de Geociências e Ciências Exatas do Campus de Rio Claro, Universidade Estadual Paulista Júlio de Mesquita Filho, Rio Claro, 2012.

O ensino de matemática em duas escolas profissionalizantes: Brasil e Portugal, no período de 1942 a 1978. 2016. 231 f. Tese (Doutorado em Educação Matemática) - Instituto de Geociências e Ciências Exatas do Campus de Rio Claro, Universidade Estadual Universidade Estadual Paulista Júlio de Mesquita Filho, Rio Claro, 2016.

NOVAES, B. W. D. Um olhar sobre a Educação Matemática nos anos 1960 e 1970 dos cursos técnicos industriais federais do Estado do Paraná. 2007. 224 f. Dissertação (Mestrado em Educação) - Programa de Pós-Graduação em Educação, Pontifícia Universidade Católica do Paraná, Curitiba, 2007.

. O Movimento da Matemática Moderna em escolas técnicas industriais do Brasil e de Portugal: impactos na cultura escolar. 2012. 235 f. Tese (Doutorado em Educação) - Programa de Pós-Graduação em Educação, Pontifícia Universidade Católica do Paraná, Curitiba, 2012.

OLIVEIRA FILHO, F. A Matemática do colégio: livros didáticos e história de uma disciplina escolar. 2013. 562 f. Tese (Doutorado em Educação Matemática) - Programa de Pós-Graduação em Educação Matemática, Universidade Anhanguera de São Paulo, São Paulo, 2013.

OTONE, M. C. Uma história da constituição da Matemática do colégio no cotidiano escolar. 2011. 291 f. Tese (Doutorado em Educação) - Programa de Estudos Pós-Graduados em Educação Matemática, Pontifícia Universidade Católica de São Paulo, São Paulo, 2011.

PINTO, A. H. Educação matemática e formação para o trabalho: práticas escolares na Escola Técnica de Vitória - 1960 a 1990. 2006. 344 f. Tese (Doutorado em Educação) - Faculdade de Educação, Universidade Estadual de Campinas, Campinas, 2006.

PIRES, I. M. P. Livros didáticos e a Matemática do ginásio: um estudo da vulgata para a reforma Francisco Campos. 2004. 141 f. Dissertação (Mestrado em Educação) - Pontifícia Universidade Católica de São Paulo, São Paulo, 2004. 
MINISTÉRIO DA EDUCAÇÃO E CULTURA. Anais do III Congresso Brasileiro do Ensino de Matemática. Rio de Janeiro: Gráfica Olímpica Editora, 1959.

RIBEIRO, D. F. C. Dos Cursos Complementares aos cursos Clássico e Científico: a mudança na organização dos ensinos de matemática. 2006. 252f. Dissertação (Mestrado em Educação Matemática) - Programa de Estudos Pós-Graduados em Educação Matemática, Pontifícia Universidade Católica de São Paulo, São Paulo, 2006.

. Um estudo da contribuição de livros didáticos de matemática no processo de disciplinarização da matemática escolar do colégio 1943 a 1961. 2011. 386 f. Tese (Doutorado em Educação) - Programa de Estudos Pós-Graduados em Educação Matemática, Pontifícia Universidade Católica de São Paulo, São Paulo, 2011.

SCHWARTZMAN, S.; BOMENY, H. M. B.; COSTA, V. M. R. Tempos de Capanema. 2. ed. São Paulo: Paz e Terra; Rio de Janeiro: Fundação Getúlio Vargas, 2001.

SILVA, E. P. A trajetória do cálculo e da disciplina de Matemática do IFSP: das escolas de Aprendizes Artificies do CEFET/SP. 2015. 120 f. Dissertação (Mestrado em Ensino de Matemática) Curso de Programa de Pós-graduação em Ensino de Matemática, Universidade Federal do Rio de Janeiro, Rio de Janeiro, 2015.

SILVEIRA, Z. S. Memória e projeto: da Escola Normal de Artes e Ofícios a CEFET/RJ. In: CONGRESSO DE HISTÓRIA DE EDUCAÇÃO, 4., 2006, Goiânia. Anais... Goiânia: Editora UCG/SBHE, 2006. v. 1, p. 1-10.

VALENTE, W. R. A Matemática do ensino secundário: duas disciplinas escolares? Revista Diálogo Educacional, Curitiba, v. 11, p. 645-662, 2011.

. História da Educação Matemática: interrogações metodológicas. REVEMAT, Florianópolis, v. 2, p. 28-49, 2007.

A Matemática do ginásio: Livros didáticos e as Reformas Campos e Capanema. São Paulo: Programa de Estudos Pós-Graduados em Educação Matemática da PUC-SP, 2004a. v. 1. CD-ROM. $2004 \mathrm{~b}$.

Euclides Roxo e a modernização do ensino de matemática no Brasil. Brasília: UNB, (org.). O nascimento da matemática do ginásio. São Paulo: Annablume, 2004c. 